Teaching Modern Macroeconomics at the Principles Level

By

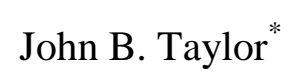

Ideas taught at the macroeconomics principles level should satisfy two goals.

First, they should be simple enough to be both understandable and memorable for the beginning student. Second, they should be consistent both with the modern economy and with the macroeconomic models of this economy that are used in practice for policy evaluation. There is no necessary conflict between these two goals. The greater the consistency between the ideas taught in the classroom and the models used in practice, the easier the ideas are to understand and the worthier they are of being remembered.

It would be an exaggeration to say that a consensus now exists in advanced research about how macroeconomics should evolve in the future. Debates continue, for example, about the usefulness of models with representative agents or what it means to have a fully articulated model of money. Nevertheless, at the practical level, a common view of macroeconomics is now pervasive in policy research projects at universities and central banks around the world. This view evolved gradually since the rational expectations revolution of the1970s and has solidified during the 1990s. It differs from past views, and it explains the growth and fluctuations of the modern economy; it can thus be said to represent a modern view of macroeconomics.

The purpose of this paper is to show how this modern macroeconomics can be taught at the principles level. I focus on macroeconomic concepts (including economic growth and fluctuations) and their graphical representation rather than on techniques of delivery, whether active learning, experiments, or the use of new media. ${ }^{2}$ The teaching 
ideas are similar to those used by Romer (2000) and Taylor (1998), but the purpose of this paper is to show how closely they represent modern macroeconomics.

\section{What is Modern Macroeconomics?}

At the broadest level I think it is useful to emphasize five key components of modern macroeconomics (see Taylor (1997)). First, the long-run real GDP trend—or potential GDP—can be understood using the growth model that was first developed by Robert Solow and that has now been extended to make "technology" explicitly endogenous. Second, there is no long run tradeoff between inflation and unemployment, so that monetary policy affects inflation but is otherwise neutral with respect to real variables in the long run. Third, there is a short run tradeoff between inflation and unemployment with significant implications for economic fluctuations around the trend of potential GDP; the tradeoff is due largely to temporarily sticky prices and wages. Fourth, expectations of inflation and of future policy decisions are endogenous and quantitatively significant. Fifth, monetary policy decisions are best thought of as rules, or reaction functions, in which the short-term nominal interest rate-the instrument of policy—is adjusted in reaction to economic events.

Economic Growth. The first and second points suggest that teaching beginning students the Solow model—augmented with endogenous technology—is the first step toward teaching them modern macroeconomics. But how much of that model is manageable by students at the principles level? In my view, the simple growth accounting formula relating labor productivity growth to the growth in capital per worker and to the growth in technology should be the center of the discussion. Trying to explain 
the steady state growth equilibrium is too abstract for beginning students and is better left for more advanced courses. In my experience it is straightforward for students to use the growth accounting formula. They enjoy using it to explain why growth slowed down in the 1970 s or to determine whether the pick-up of growth since the mid 1990s in the United States (a key feature of the "new economy") is due to more capital or to better technology. Students sometimes find that the formula is too mechanical, and providing an intuitive explanation of it is helpful. (One could derive the formula graphically using shifts and movements along a production function, or present a Cobb-Douglas production function and compute total factor productivity using data on labor and capital, but these raise the level of difficulty for many students and are probably better left for more advanced courses.) The technology term in the growth accounting formula is useful for focusing attention ( $a$ la endogenous growth theory) on the determinants of technology growth, including education, research and development, and the process of invention and innovation.

Economic Fluctuations. While the growth accounting formula is useful for explaining long-term growth in the economy, other factors- the short-run tradeoff, expectations, and monetary policy—must be brought into play in order to explain fluctuations of real GDP around the growth trend. Fortunately there is a simple approach—comparable with the supply and demand model—that can be used to explain these fluctuations in much the same way they are explained in modern macroeconomic policy research.

If you look carefully at macroeconomic policy research in the 1990s, you find a nearly universal model being used to explain fluctuations around the growth trend. Many 
examples are found in the papers reviewed in the useful survey by Clarida, Gali, and Gertler (1999). Virtually all of the participants in a recent NBER conference on monetary policy evaluation used this type of model (see Taylor (1999)). And models now used for policy evaluation at the Federal Reserve, the European Central Bank, the Bank of Canada, the Bank of England, the Reserve Bank of New Zealand, and the Central Bank of Brazil also fall into this category.

Some of these models (such as Rotemberg and Woodford (1997) or Svensson (2000)) are more explicitly tied in with microeconomic foundations than others. Some of the models are very small, with only three equations (such as Fuhrer and Madigan (1997)) and some have many equations. But all the models can be boiled down to three relationships and three variables:

(1) The first relationship is between real GDP and the real interest rate. Such a relationship can be explained intuitively to principles students, but I can use some algebra here. The simplest algebraic form would be $y=-a r+u$ where $y$ is real GDP (measured relative to the potential GDP that comes from the Solow growth model), $r$ is the real interest rate, and $\mathrm{u}$ is a shift term such as a shock to exports or fiscal policy. This relationship is analogous to an IS curve. It describes how a higher real interest rate depresses the demand for good and services in the economy. The equation can be derived as the first order condition of an intertemporal maximization problem (see Clarida, Gali, and Gertler (1999)). Such a derivation would include a lead of output on the right hand side. It can also be derived using a Keynesian cross diagram in which the aggregate expenditure line shifts down with a higher interest rate. I find that most students are satisfied with an intuitive explanation that higher interest rates discourage investment, net 
exports (because a higher interest rate raises the exchange rate), and consumption, thereby driving down demand.

(2) The second relationship is between inflation and the real interest rate. The simplest algebraic form would be $r=b \pi+v$ where $\pi$ is the inflation rate and $\mathrm{v}$ is a shift term. This equation is a close approximation to the actual behavior of many central banks. When the inflation rate rises the central bank takes actions to raise the short-term interest rate (the federal funds rate in the United States) by enough to raise the real interest rate (b should be positive); this action is aimed at keeping inflation from rising further and bringing it back down. Central banks must decide how much to raise interest rates in response to inflation, taking the likely impact on unemployment or real GDP into account as well. In policy research other terms such as real GDP are generally included in the policy rule, but at the principles level it is much easier do keep the reaction to one variable. Observe that this characterization of monetary policy in terms of the interest rate is different from earlier principles treatments where money is assumed to be fixed or targeted by central banks; in reality modern central banks make decisions about the short term interest rate and much policy research suggests that this is to be preferred to a quantity oriented policy, at least with current and expected future behavior of money demand.

(3) The third relationship is between inflation and real GDP. This is a standard expectations-augmented Phillips curve in which the change in inflation increases when real GDP rises above potential GDP, signaling demand pressures. The simplest algebraic form of this relationship is $\pi=\pi_{-1}+\mathrm{cy}_{-1}+\mathrm{w}$ where $\mathrm{w}$ is a shift term; thus inflation rises with a lag when $y$ is greater than zero. The modern derivation of this equation is in terms 
of staggered price setting by firms with some degree of market power. Here again one would expect to find leads of inflation in the relationship, so that expectations of inflation would raise actual inflation. Again see Clarida, Gali, and Gertler (1999) for example.

\section{A Simple Graphical Representation of Economic Fluctuations}

In more advanced courses or in research work, it is of course possible to solve the three equations in three unknowns ( $\mathrm{y}, \mathrm{r}$ and $\pi$ ) as functions of the shocks $(\mathrm{u}, \mathrm{v}$, and w). Thus one can investigate how the economy responds to shocks and study normative policy questions such as how large the coefficient $b$ in the policy rule should be. One can even do this with forward-looking variables and with rational expectations and consider the three shocks simultaneously as random variables.

But at the principles level we need a much simpler approach. Fortunately it is possible to construct a diagram that captures the essence of the models in a very simple way. Combining (1) the real GDP/interest rate relationship and (2) the central bank policy rule gives a negatively sloped relationship between inflation and real GDP. This relationship is an aggregate demand relationship, labeled AD in Figure 1. This relationship can be explained intuitively to beginning students, but we can derive it algebraically here by substituting the algebraic form of (1) into the algebraic form of (2) to obtain $y=-a b \pi+u-a v$. Movements along this relationship occur when inflation (shown on the vertical axis) changes and the central bank changes the real interest rate causing real GDP (shown on the horizontal axis) to change. For example, when inflation rises, the central bank raises the real interest rate and this causes real GDP to fall. The $\mathrm{AD}$ curve shifts to the right if there is a positive export shock or a fiscal stimulus. 
Observe that this $\mathrm{AD}$ curve is relationship between the inflation rate and real GDP rather than between the price level and real GDP. I have previously labeled this curve ADI, with the "I" for inflation, to remind teachers that it differs from other aggregate demand curves; Romer (2000) labels the curve AD, as I have done in Figure 1.

Relationship (3) can also be represented in Figure 1. It is a flat line, labeled IA. The IA line shifts up over time when real GDP is above potential GDP and shifts down over time when real GDP is below potential GDP. The line would be upward sloping if current real GDP rather than lagged real GDP affected inflation, but the flat case is realistic and easier for students. Because this line represents the slow adjustment of prices or of the inflation rate, it could be called either the price adjustment (PA) line or inflation adjustment (IA) line. The line takes the place of the aggregate supply relationship in AD-AS treatments. Following Romer (2000), I label it IA in Figure 1. Real output and inflation are determined at the intersection of the AD and IA curves in Figure 1. How does one explain the effect of a demand shock or an inflation shock? Suppose there is a fiscal stimulus; suppose it is permanent rather than temporary. This stimulus shifts the AD curve to the right, and there is a new intersection. GDP rises, but, in the short run, the inflation rate does not rise. Over time, however, the inflation rate does rise and the IA line shifts up. The IA line continues to shift up until real GDP is back to potential and the inflation rate is higher. If the central bank wanted to offset this higher inflation rate then in would have to shift the AD curve back down again. This would cause a slow down or a recession as real GDP fell below potential GDP. The analysis is no more complicated than shifting supply and demand curves in elementary microeconomics. And because the inflation rate rather than price level is on the vertical 
axis there is no need to keep shifting the curves up and up and up until they are off the page to describe a steady inflation.

\section{Micro before macro? One-term or Two-Term Courses?}

What implication does teaching modern macroeconomics in this way have for how principles courses are organized? In my view it suggests that microeconomics be taught before macroeconomics. Certain concepts like treating capital and labor as factors of production, or shifting demand curves around, are probably better understood after some microeconomics. If one cannot practically require that micro be taken before macro (because of scheduling conflicts or resource constraints), then it is important for the macro course to spend some serious time covering key micro principles.

An alternative is to offer a one-term introductory course with microeconomics coming before macroeconomics. This is the way elementary economics is taught at Stanford and I think the simple approach to teaching modern macroeconomics outlined here helps make a one-term course work. But many faculty members feel that there is too much economics to teach in one term.

\section{Conclusion}

In this paper I have argued that there is a distinctive modern form of macroeconomics that is now being used widely in practice, even though research on potentially better models continues and disagreement about the best way to proceed persists. This theory fits the data well and explains policy decisions and impacts in a realistic way. Whether you call it the "new neoclassical synthesis," reminiscent of Paul Samuelson's original textbook treatment of his "original neoclassical synthesis," or something else, I think it is both appropriate and possible to teach this modern form of 
macroeconomics at the principles level..$^{\text {B }}$ I recognize that there are many alternative ways to teach macroeconomics and that what works well for one teacher and his or her students may not be attractive to others. I can say that the ideas that I have suggested here have worked well for my students and me, as well as for others that have used them.

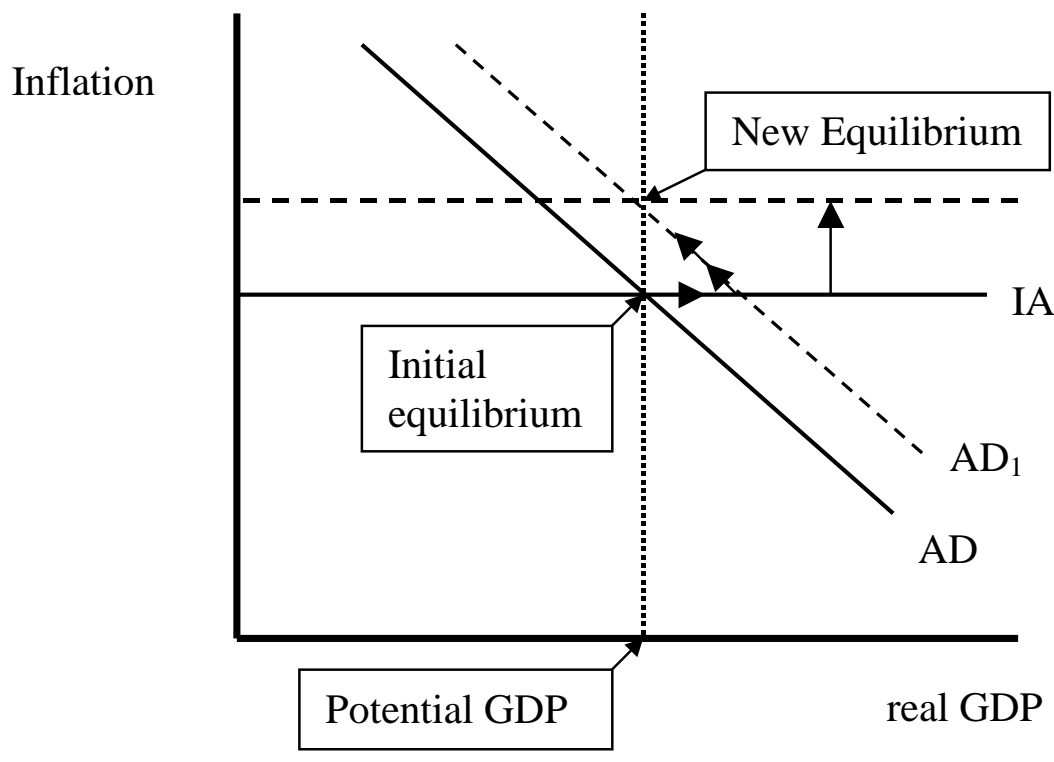

Figure 1. Graphical illustration of a modern view of macroeconomics. Starting from an initial equilibrium, a fiscal shock causes the $\mathrm{AD}$ curve to shift to the right to $\mathrm{AD}_{1}$ increasing real GDP. Then the IA curve begins to shift up gradually until there is a new equilibrium. A shift in monetary policy would be required to bring inflation back down. 


\section{References}

Clarida, Richard, Jordi Gali, and Mark Gertler, "The Science of Monetary Policy: A New Keynesian Perspective," Journal of Economic Literature, 1999, 37 (4), pp. 1661-1707.

Clerici-Arias, Marcelo and John B. Taylor, "Surprise Side Economics: Ideas for Introductory Economics Lectures," Stanford University, January 2000. Slides at www.econ1.com

Fuhrer, Jeffrey C. and Brian F. Madigan, "Monetary Policy When Interest Rates are Bounded at Zero," Review of Economics and Statistics, 1997, 79, pp 573-585.

Goodfriend, Marvin and Robert King, "The New Neoclassical Synthesis and the Role of Monetary Policy," in Ben Bernanke and Julio Rotemberg, eds., Macroeconomics Annual, Cambridge: MIT Press, 1997, pp. 231-282.

Romer, David, “Keynesian Macroeconomics without the LM Curve.” Journal of Economic Perspectives, 2000, forthcoming

Rotemberg, Julio and Michael Woodford, “An Optimization Based Econometric Framework for the Evaluation of Monetary Policy," in Ben Bernanke and Julio Rotemberg, eds., NBER Macroeconomics Annual, Cambridge Massachusetts: MIT Press, 1997, pp. 297-346.

Svensson, Lars E.O., "Open-Economy Inflation Targeting, " Journal of International Economics, 2000, 50 (1), pp. 155-183.

Taylor, John B. “A Core of Practical Macroeconomics.” American Economic Review, May 1997, (Papers and Proceedings), $\underline{87}$ (2), pp. $233-235$.

Taylor, John B. Economics, Second Edition. Boston: Houghton-Mifflin, 1998.

Taylor, John B. (Ed.), Monetary Policy Rules. Chicago: University of Chicago Press, 1999.

Taylor, John B. and Michael Woodford (Eds.), Handbook of Macroeconomics. Amsterdam: North Holland, 1999. 
${ }^{*}$ Stanford University, Stanford, California, 94305 . This paper was prepared for presentation at the session "Teaching Macroeconomic Principles" at the Annual Meetings of the American Economic Association, Boston, Massachusetts, January 7, 2000. I am grateful to Michael Salemi and Marcelo Clerici-Arias for helpful comments.

${ }^{1}$ The preface and many of the papers in Taylor and Woodford (1999) describe such an evolution. Various names have been suggested for the macroeconomic approach that is now so common including "new neoclassical synthesis" (Goodfriend and King (1997)) or "new Keynesian economics" (Clarida, Gali, and Gertler (1999)).

${ }^{2}$ Ideas for lectures in introductory economics are discussed in the presentation by ClericiArias and Taylor (2000) in the session "Computer Assisted Instruction: Teaching Economic Principles." at the American Economic Association meetings, January 9, 2000. ${ }^{3}$ It is important to point out that this framework for teaching economic growth and economic fluctuations is perfectly consistent with the pre-college Content Standards endorsed by the American Economic Association's Committee on Economic Education. The Content Standards include the ideas that money facilitates economic exchange, that the interest rate affects investment and saving, that real income growth is determined by productivity growth, that investment raises capital and thereby raises productivity, that unemployment and inflation are costly, and that fiscal and monetary policy have impacts on output and inflation (these are short paraphrases of standards 11, 12, 13, 15, 19, and 20, respectively). However, the above framework provides greater specificity and detail appropriate at the college level. In my view this specificity helps students tie the content standards together, learn how they are used in practice, and remember them. 